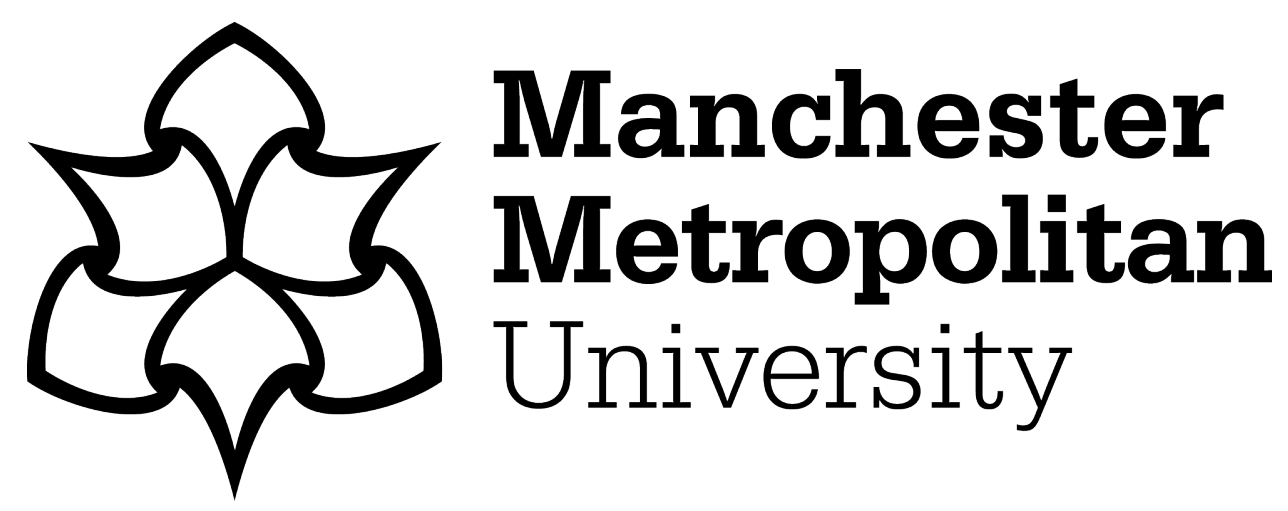

Leal Filho, Walter, Ellams, Dawn, Han, Sara, Tyler, David, Boiten, Valérie Julie, Paco, Arminda, Moora, Harri and Balogun, Abdul-Lateef (2019) A review of the socio-economic advantages of textile recycling. Journal of Cleaner Production, 218. pp. 10-20. ISSN 0959-6526

Downloaded from: https://e-space.mmu.ac.uk/622434/

Version: Accepted Version

Publisher: Elsevier BV

DOI: https://doi.org/10.1016/j.jclepro.2019.01.210

Usage rights: Creative Commons: Attribution-Noncommercial-No Derivative Works 4.0

Please cite the published version 


\title{
A Review of the socio-economic advantages of textile recycling
}

\author{
Leal Filho, W., Ellams, D., Han, S., Tyler, D., Boiten, V., Paço, A., Moora, H., Balogun, A-L. 2019. A \\ Review of the socio-economic advantages of textile recycling. Journal of Cleaner Production, \\ Volume 218, 1 May 2019, 10-20 | https://doi.org/10.1016/j.jclepro.2019.01.210
}

\begin{abstract}
The textile/apparel industry is of great importance to the economy in terms of trade, employment, investment and revenue all over the world. This sector is however characterised by substantial losses, due to production excesses on the one hand, and the "throw away" culture on the other. This state of affairs suggests that textile recycling is needed. Apart from the environmental and ecological advantages which can be brought about by the re-use and recycling of textiles, there are many benefits of a socio-economicnature. This paper analyses current trends on textile recycling, the barriers impeding greater recycling, and outlines the socio-economic advantages of moving towards a circular economy. Some examples of on-going initiatives are discussed, together with some of the measures that may be used to further reduce the current waste deriving from the apparel sector.
\end{abstract}

Key words: Socioeconomic; Textile; Recycling; Re-use; Production; Processes; circular economy

\section{Introduction}

The apparel industry is of great importance to the economies of every country in terms of trade, employment, investment and revenue. In 2015, the size of the global apparel market reached USD 1685 billion (Statista, 2018). At the same time, supply chain processes are characterized by fragmented and relatively low-tech systems, which have major environmental impacts such as the use of large quantities of water and chemicals, high emissions of greenhouse gases and generation of waste (Remy et al., 2016). A recent attempt to assess the global impact of the textile sector is by the Ellen MacArthur Foundation (2017) in "Appendix B.2: Resource use and negative externalities associated with material flows". Global annual figures are given for: Total Greenhouse Gas Emissions (GHG) (1200 million tonnes); water usage (93 billion cubic metres); fertilisers for cotton (8 million tonnes); pesticides for cotton (200,000 tonnes); chemicals (42 million tonnes) and dyestuffs (1 million tonnes). For comparison purposes, the greenhouse gas emissions for cotton production are estimated as $4.7 \mathrm{~kg} \mathrm{CO}{ }_{2} \mathrm{e} / \mathrm{kg}$ fibre; for plastic-based fibres production are estimated as $11.9 \mathrm{~kg} \mathrm{CO} 2 \mathrm{e} / \mathrm{kg}$ fibre; for yarn and fabric production, including dyeing, are estimated as $9.6 \mathrm{~kg}$ $\mathrm{CO}_{2} \mathrm{e} / \mathrm{kg}$ fibre. Regarding water usage requirements: the figure for cotton production is estimated as 4600 litre/kg fibre; for plastic-based fibre production is estimated as 38 litre/kg fibre; and for dyeing textile materials is 88 litre/kg fibre. 
The share of textiles in total municipal solid waste generation in 2014 in USA accounted for over six percent (16.22 million tonnes), out of which 16.2 percent (2.62 million tonnes) was recycled, and 64.5 percent was landfilled (U.S. EPA, 2016). The EU textile industry generates waste estimated at 16 million tonnes per year. Much of this waste is incinerated (European Commission, 2017). According to the Ministry of Environment of Korea between 2008 and 2010, textile waste volume increased by 17 percent, from 54,677 to 64,075 tonnes, respectively (Kim and Kim, 2016). The reuse and recycling of textiles could be considered as a route to socio-economic benefits and a means of boosting a nation's economy (Cuc and Vidovic, 2011). Indeed, the advocacy for a "circular economy" (Ellen McArthur Foundation, 2016), in which materials continue to circulate in the economic system in a cascade of reuse and recycling, has been gaining strength as it is translated into commitments made by policy, business and civil society representatives. In a report commissioned by the European Union, consultancy firm McKinsey estimates that the transition to a circular system could generate a net economic benefit of $€ 1.8$ trillion by 2030 (McKinsey, 2015). More recently, reports by the Club of Rome have concluded that the circular economy would deliver socio-economic benefits in the form of enhanced energy efficiency, reduced carbon emissions and the creation of employment in the EU (Wijkman \& Skånberg, 2016). For the textiles sector specifically, an economic system in which fabric and fibre recycling is fully integrated, has been said to reduce resource needs (water, fossil fuels, chemicals) and to generate new jobs in the collection, sorting and recycling of clothing (Ellen McArthur Foundation 2017). These socio-economic benefits have been widely projected, yet the available evidence remains scarce. By reviewing the literature, this paper aims to address the gap between circular economy thinking and proof-of-concept for textile reuse and recycling.

Most of the contemporary social advantages of textile reuse and recycling are related to charity activities. For instance, in the UK, charity organizations collect textile waste and resell it through their shops, and surplus stocks are sold to recycling firms (Kim and Kim, 2016). The contents of clothing banks belonging to charities are directly collected by recycling firms which compensate the associated charity based on the weight of the collection (Bianchi and Birtwistle, 2010). The earned profit is closely tied with internal and external activities and projects to help people and communities where carers and supporters are needed (Kim and Kim, 2016).

In Brazil, recyclable waste collectors, most of whom live in poverty, are integrated into a cooperative or association and supported by local government. They contribute to neighbourhood improvement, waste cleaning, demonstrating resource recovery behaviours, and creating opportunities for greater community cohesion (Baruque-Ramos et al., 2017).

Every phase of the life cycle of textile waste recycling (i.e. collection, sorting, transport, recycling) creates employment and gives opportunities for small or family businesses (Cuc and Vidovic, 2011; Zamani, 2014). More often, textile recycling is considered not as an end in itself, but as a route to implement the circular economy, i.e. a closed loop production system. It could become one of the solutions that helps companies in the process of moving towards sustainable business performance. Textile recycling leads product manufacturing towards a reduction of production costs, depending on recyclable materials being a low-cost and efficient alternative with low environmental impact. As an example, ECOSIGN (2017) reported that recycling secondhand clothes could reduce 
greenhouse gas emissions by $53 \%$, reduce pollution associated with chemical processing by $45 \%$, and reduce water eutrophication levels by $95 \%$.

The recycled materials could be applied in many fields such as automotive, furnishing, sailing and/or insulation, e.g. for production of geo-fleece, carpet underlay, rear shelves in car, stuffed toys, shoe insoles, etc. (Ishfaq, 2013; ECOSIGN, 2017). Part of the waste produced in the areas of spinning and weaving can be forwarded to recycling units, where they are subjected to a process of fibre recovery (Nunes et al., 2018). Recycled fibres then become a constituent part of the pool of resources of the textile/clothing industry similar to natural fibres such as cotton or linen, allowing the generation of additional value (Ribeiro Rosa, 2016).

The sharp changes in the textiles' market and the uncertainty around some key export markets have highlighted the need for market development for recycled grades, including closed loop fibre-tofibre recycling (WRAP, 2016). It creates an opportunity for new start-ups to enter the market by dedicating their economic activity to textile recycling utilizing advanced technologies to produce high valued-added products (Cuc et al., 2015; Ribeiro Rosa, 2016). According to the WRAP projections, the following end markets are considered of the highest potential with the following revenue by 2020 in the UK only: insulation - approximately $£ 45$ million; automotive felt - $£ 3.3$ million, wipers, which are cotton based cloths that are used for cleaning and polishing purposes in various industries such as print, mining, heavy oil and mechanical and aviation - $£ 28$ million; flocking, recycle grade textiles shredded to be used as fillings in the mattresses and furniture industry - $f 9$ million, and fibre to fibre or chemical recycling with two key segments: Polyamides (e.g. Nylon) and Polyesters that might reach $\mathrm{f} 90$ and $f 105$ million respectively (WRAP, 2014).

Textile recycling is also perceived as one of the key directions needed for a sustainable transition of the sector. By responding to a rising recognition that the industry should take responsibility to reduce its pressure on raw resources in the face of growing global populations, fashion brands have started to incorporate textile-to-textile recycling in the production of their products (Watson et al., 2017).

For instance, the Finnish brand Pure Waste, founded in 2013, produces clothing using its own yarns made from $100 \%$ recycled materials. The company puts the main focus on pre-consumer textile waste such as waste yarn (mostly cotton) from textile mills, and coloured off-cuts from textile factories. H\&M began using recycled materials in 2009, and in 2010 launched the first Conscious collection. The company is also the second largest global user of recycled polyester for textiles (Watson et al., 2017). Another successful example is Patagonia's WornWear Program, the Common Threads Recycling Program, USA (Patagonia, 2017). The company has successfully incorporated textile recycling technologies into product development and innovative design. This approach brought continuous positive financial results and 2015 was the most profitable year in the company's history (Ribeiro Rosa, 2016). The Brazilian Ecosimple brand created in 2010 uses 100\% recycled materials in its fabrics and brand products. The company presents itself in the Brazilian textile context as a company that uses innovation by adopting a production model that minimizes environmental impact and favours poor communities (Broega et al., 2017).

The environmental benefits of textile reuse and recycling have been addressed recently by Sandin and Peters (2018), who reviewed 41 publications. A major conclusion is that reuse and recycling in general reduce environmental impacts, mainly because the need for primary resources is reduced. 
However, environmental benefits are not the only consequences of circular economy initiatives. The EU Commission's policy document on the circular economy (2015) envisages benefits in helping to create new business opportunities, delivering innovative, more efficient ways of producing and consuming, and create opportunities for social integration and cohesion. These are socio-economic and socio-environmental benefits which are worthy goals, but the evidence base to support the claims is weak. Lieder and Rashid (2016) review literature on the transition to circular economy across many manufacturing sectors. However, there is very little on socio-economic benefits, and the topic is mostly covered by the phrase: "analysis of a broader approach that places human activity into a long term CE perspective". Fischer and Pascucci (2017) refer to socio-environmental impacts at a system level, but this is only in their discussion of Product-as-Service arrangements. With the service provider having greater responsibility, there is an incentive to improve quality and environmental performance. The benefits are "expected" but documentation has yet to take place. The focus of this review is to document examples of socio-economic impacts arising from circular economy initiatives. The cases reported are analysed to show what has and what has not been achieved. The gap in the literature resides on the fact that there is a paucity of European studies which look at the issue of textile recycling in an integrated way, so a scientific study of the topic is a timely effort. The novelty of the paper resides on the fact that it clarifies the content of socioeconomic benefits, identifies achieved socio-economic benefits, and also points out others that have yet to be achieved.

\section{Methods}

\subsection{Literature review}

The socio-economic benefits of textile reuse and recycling are evaluated to identify potential opportunities and highlight lessons from successful initiatives, particularly in technologically advanced countries in Europe and South America. Thus, a systematic literature review has been conducted, adapting the six-step and five-step models implemented by Machi and McEvoy (2009) and Garcia-Granero et al. (2018) respectively. Problem definition and topic selection; selection of sources; literature selection; critical evaluation of studies; synthesis and review writing were done in a sequential manner. This integrated approach has the merit of including a significant volume of information in the search, thereby providing detailed and reliable information for diverse stakeholders. This is in addition to addressing queries directly related to the topic as well as discovering new opportunities for further research.

In defining the problem and selecting an appropriate topic, we focused on the research's overarching objective, which is to identify the advantages of textile reuse and recycling, with an emphasis on the socio-economic perspective. This step was followed by the selection of sources for the research. According to Levy and Ellis (2006) as reported in Kuo and Smith (2018), top quality resources are essential requirements for a good literature review. The use of highly ranked publications sourced from multiple databases facilitates a structured, reliable, and effective literature review capable of providing valuable insights for future initiatives. Literature searches were based on some of the most valuable repositories of scientific research data, including Web of 
Science, Scopus, and Google Scholar. These are major databases for rigorously reviewed journal articles. We also used ProQuest to search for relevant theses and dissertations. The scope of literature sources was extended to include Google. This was necessary to make sure that relevant publications, which are not included in scientific databases, were not omitted. Subsequently, literature search and selection was undertaken based on queries in the aforementioned databases. The query was formulated using structured search string based on Boolean operators and keyword search. The following search string were used:

[textile OR clothing OR garment OR apparel OR fibre OR microfiber OR fabric] AND [waste OR reuse OR recycling] AND [world OR global OR Europe OR NORDIC OR Brazil] AND [impacts OR pollution OR barriers OR challenges OR disadvantages] AND [environmental benefits OR economic benefits OR social benefits] AND [businesses OR workers OR consumers OR local community OR society]

In a recent review paper, Sandin and Peters (2018) used the following search string: ["life cycle assessment" OR "life cycle analysis" OR LCA OR (environmental OR energy) AND (assessment OR evaluation OR analysis) AND (textile OR clothing OR garment OR fashion OR apparel) AND (recycling OR reuse OR "collaborative consumption" OR "second hand" OR library OR sharing OR leasing)]. The core terms used in our search string are similar to this. However, we point out these variants: Sandin and Peters (2018) are interested in environmental impacts and use LCA terms to track these. These authors also extend the reuse and recycling terms by incorporating other modes of giving products a second life. Regarding our paper, we expand the textile terms to include fibres and fabrics, add geographical terms (as we are looking for specific cases rather than concepts) and add a requirement for impacts of a social or economic nature.

Thereafter, critical evaluation and appraisal of the selected literature was initiated. Manuscripts which did not discuss textile reuse or recycling in a comprehensive manner were excluded. Newer papers were prioritized to ensure the state-of-the-art of textile recycling research was adequately covered. Table 1 shows the distribution of references used based on publication year. Although no strict restriction was placed on the publication date, majority of the references were from 2015 upwards. Papers from major publishers such as Emerald, Ebsco, Elsevier, Springer, Taylor \& Francis, Wiley were studied.

Regarding exclusion criteria, duplicated studies were excluded and, for instance, if a paper from a conference proceeding was revised and published in a peer-reviewed journal, preference was given to the latter while removing the former. We also excluded articles that are not coherent even if related to our central theme, while extra caution was taken when reviewing newsletters and reports obtained from Google search since these are usually not peer-reviewed. The first database search yielded several documents, which were assessed for relevancy through the analysis of the abstracts at a first screening stage decreasing the sample significantly. Out of the remaining eligible documents, a few more were excluded as they were considered not relevant to the study. The criterion of including studies performed exclusively in the textile context decreased the final sample to 85 documents, which increased in more recent years (as in 2015 - 2018), as observed in Table 1. 
Table 1: Publications on textile recycling used in this review

\begin{tabular}{ccc}
\hline Year of Publication & Frequency & Percentage (\%) \\
\hline 1998 & 1 & 1.14 \\
2006 & 3 & 3.41 \\
2007 & 1 & 1.14 \\
2009 & 1 & 1.14 \\
2010 & 6 & 6.82 \\
2011 & 4 & 4.55 \\
2012 & 3 & 3.41 \\
2013 & 4 & 4.55 \\
2014 & 7 & 7.95 \\
2015 & 13 & 14.77 \\
2016 & 17 & 19.32 \\
2017 & 14 & 15.91 \\
2018 & 13 & 14.77 \\
N.D & 1 & 1.14 \\
Total & 88 & \\
\hline & &
\end{tabular}

Based on the analysis of the various studies, our paper was segmented to cover four related aspects of textile recycling: trends on textile recycling in Europe; barriers to textile recycling; examples of socio-economic benefits of textile recycling; and lessons learned. Details of these are presented in subsequent sections. Being the central-theme of this review, the methodology for deducing the socio-economic advantages of textile reuse and recycling is further elaborated in the next section.

\subsection{Examples of socio-economic benefits of textile recycling}

The first four sections of this paper provide an overview of the subject matter of textile reuse and recycling. The last part (Section 5) provides some examples, which show what can be achieved by textile recycling from a socio-economic point of view. To this purpose, two main procedures were followed:

1. A review of the literature, picking examples of textile reuse and recycling in a developing country, namely Brazil

2. An analysis of examples from developed countries, specifically Nordic countries 
The study was performed as a desk research, using the systematic approach presented in Section 2.1. In addition to scientific publications, information provided by official reports and documents produced by well-established organisations were also utilized in the literature study.

Given the already discussed advantages of textile reuse and recycling, it is appropriate to present some examples illustrating good practices in the sector. In countries such as Brazil and the Nordic countries (e.g. Finland, Sweden, Denmark) there are relevant projects and business models that illustrate how the textile reuse and recycling models could have economic and social benefits, empowering consumers, suppliers and involved workers as well as adding value to businesses and communities.

\section{Trends on textile recycling in Europe}

The environmental impacts of textile production, consumption and disposal are increasingly considered in societal, business and research debates, with varying degrees of statistical data and impact measurements provided. When it comes to the production stages of the textile value chain, attention has been given to ecological impacts resulting from cotton agriculture, such as biodiversity loss due to the use of pesticides and other toxic substances as well as water depletion (Chapagain et al., 2006). While tanning and dyeing processes adversely impact soil, water and atmospheric systems due to their release of toxic pollutants such as chlorinated phenols and chromium (Mwinyihija, 2010), the finishing and coating tend to involve hazardous substances impacting humans and environmental health, for example in the application of flame-retardant and waterrepellent finishes (De Smet et al., 2015). The textile industry takes a heavy toll on ecosystems and in particular freshwater provision: it is estimated that globally, $20 \%$ of all industrial water pollution comes from the dyeing and treatment of textiles (Kant, 2012).

Considerably less attention however has been devoted to the use-phase of textile and clothing products. According to the European Clothing Action Plan, this phase may well account for one third of the environmental impacts caused throughout clothing products' lifespan (Gray, 2017). This is mostly due to the high energy demand of frequent washing and drying habits. More recently, researchers as well as civil society activists have attempted to shed light on plastic microfiber pollution shed by synthetic clothing during washing. Per PET fleece garment and per wash, an estimated 110,000 microfibers enter the oceans via wastewater routes (Carney Almroth et al., 2018).

Literature points to a persistent lack of standardised Life-Cycle Assessment studies of the textile and clothing supply chain, caused by strong dependencies on the data used, the assumptions made, the chosen LCA-method and the impact categories considered (Sandin and Peters, 2018). At the same 
time, the lack of consistency and sheer availability of data inventories on the use and impacts of chemical substances continue to hamper assessments of the textile industry's environmental performance (Piontek and Müller, 2018).

Global textile fibre production has grown from an estimated 70.6 million tonnes in 2007 to 85.5 million tonnes in 2013 and 90.8 million tonnes in 2014, with production forecasted to reach 130 million tonnes by 2025 (Dahlbo et al., 2017; Pensupa et al., 2017). In 2012 the commercial textile trade was valued at $\$ 1.8$ trillion worldwide, with China and India the top two producers (Dahlbo et al., 2017). In 2013, the EU clothing and textiles sector had a turnover of $\$ 166$ billion, accounting for $6 \%$ of total employment in manufacturing in Europe (European Commission, 2015b). The EU clothing and textiles sector comprised of 185,000 companies which employed 1.7 million workers. Companies with less than 50 employees accounted for more than $90 \%$ of the workforce and produced almost $60 \%$ of the value added, indicating that the sector is based around small businesses (European Commission, 2015b).

Activity in the EU clothing and textiles sector is focused in five main cluster regions of Tuscany, Northern Greece / South Bulgaria, Eastern Slovakia, Nord Pas de Calais / Flanders and Northern Portugal / Galicia (Pellizari et al., 2011). The EU industry has seen radical changes in which some companies have maintained and strengthened competitiveness by reducing mass production and concentrating on a wider variety of higher value added products, through quality, design and technological innovation. Indeed the high-end sector grew faster than the rest of the European economy during the recent economic crisis, employing over 1 million people, exporting over $60 \%$ of production outside Europe, and accounting for 10\% of all EU exports (European Commission, 2015a).

Threats to this economic advantage include 'the increased prevalence of counterfeit goods, increasing shortages of skilled workers, and difficulties for small and medium-sized fashion enterprises to access finance' (European Commission, 2015a). Pellizari et al. (2011) characterise some of the main difficulties the European textiles and clothing sector as being globalisation and internet based technologies in a market dominated by low prices, cheap imports and international sub-contracting. Value chains in specialised areas of manufacturing or industrial clusters have been disrupted by these international trade relations, affecting support services and industrial development. The EU sector relies heavily on imports, and in 2008 the European Union accounted for nearly half (47.3\%) of total world apparel imports of US\$376 billion (Gereffi and Frederick, 2010). 
The overall image of the sector as a low-profit, low innovation industry with low wages and questionable working conditions has vastly reduced its attractiveness to young workers and professionals, making the recruitment of a skilled workforce problematic. Added to this are difficulties finding credit, regions where entrepreneurship is underdeveloped and a lack of easily identifiable best practice enterprise examples (Pellizari et al., 2011). To continue to mitigate further threats from trade liberalisation, increasing external competition, consumer developments, technological advances, changes in production costs and environmental issues, the sector must continuously reinvent business models (European Commission, 2015a).

While various attempts have been made to quantify the volumes of available textile waste across Europe, it has proved challenging to overcome the inconsistency in classifying, quantifying and reporting waste. Textile collection systems vary greatly between the European countries. It is estimated that between 15 and $25 \%$ of the overall available textile waste is collected separately and hence enters potential reuse or recycling routes (Zamani, 2014). In a recent market study carried out on behalf of the Resyntex project, Oakdene Hollins (2016) quantified the fraction of textile waste that is mixed in municipal or industrial waste streams in the EU at 9.35 million tonnes. This fraction is landfilled or incinerated, with energy recovery for the letter option.

In France, textile materials that are collected separately (210 000 tonnes in 2016, i.e. 3,2 kilos per inhabitant) are largely reused through overseas exports of second-hand clothes (60\%), while around $32 \%$ are shredded and downcycled into nonwovens, insulation felts and cleaning wipes (Eco-TLC, 2016). Around $7,5 \%$ is incinerated to produce energy (EfW). Belgium has very comparable figures, although the percentage of fibre reuse through shredding is higher (47\%) (Coberec, 2016). As highlighted by these figures, the collection of textile waste remains dominated by the quest for highquality and reusable (i.e. rewearable) clothing. This reuse fraction is followed by recycling activities, usually by means of mechanical processes that are considered "downcycling" due to the loss of fibre strength and quality. The collectors' profession is hence focused on product rather than material. This can be explained by the fact that the technologies to sort, separate and process singular fibre types (which are often mixed in blends) are still at the development stage, and not yet upscaled to industrial practice. As a result, the collection of non-reusable textiles presents an economic cost (collection, transport, sorting) that is not outweighed by its subsequent value through recycling.

Traditionally, a distinction is made between chemical and mechanical recycling. However, as Sandin and Peters (2018) point out, recycling routes often consist of a mix of mechanical, chemical and 
thermal processes. To overcome this ambiguity, they distinguish between recycling routes based on the level of disassembly of the recovered material: fabric recycling, fibre recycling, polymer/oligomer recycling, monomer recycling. For clothes and textiles unsuitable for reuse, recycling into new fibres, feedstocks, materials and products ensures full circularity. Michaud et al. (2010) broadly categorise three types of textile recycling: wiper production, fibre materials and respun fibres made into new fabric products. The process of converting post-consumer textiles into wipers involves removing any metallic parts such as zips, before cutting into the relevant size for sale to industry. Although over 21,000 tonnes of collected textiles were sent to wiper production in the UK in 2010, an 83\% decline in market value was experienced between 1990 and 2009 (Bartlett et al., 2013). The environmental benefits from wiper production as a form of textile recycling stem from the replacement of virgin materials such as cotton cloths or paper, however limited demand for recycled wiping clothes necessitates the development of alternative routes for these materials (Michaud et al., 2010).

Post-consumer and pre-consumer textiles can also be used as feedstock in the production of fibres for filling materials such as flocking, insulation and nonwovens, and in the production of shoddy fibres for recycled yarns (Bartlett et al., 2013). For these purposes, textiles are recycled mechanically in processes which cut and shred fabrics into fibres which can then be respun into yarn or made into nonwoven textiles (Payne, 2015). Flocking is comprised of shredded textiles combined with wool to create a fire retardant product, and is used for filling in mattresses and furnishings. Although the market for flocking is in decline, demand is still strong as local sourcing is more competitive due to transport logistics and high import costs (Bartlett et al., 2013).

Nonwovens are created from bonded layers of shredded textile fibres and used for purposes such as insulation and carpet underlay. For nonwovens, ease of processing and quality is determined by the grade of the textile feedstock (Bartlett et al., 2013). These forms of physical and mechanical textile recycling can be classified as open-loop systems, in which products are broken down to be used in a secondary and unrelated product system. Material savings can be made at this stage by replacing virgin materials, however often no provision is made for re-collecting these materials at their second end-of-life stage, and were these items to be collected, continual reprocessing would degrade the quality materials beyond usefulness (Payne, 2015).

Both post-consumer and pre-consumer textiles can be mechanically recycled into fibres, used to produce new yarns and fabrics, and made into clothes, blankets or knitted products. Shorter fibre 
lengths result in poorer quality textiles and it is necessary to combine the recycled fibres with new to achieve the required properties (Bartlett et al., 2013). Technical closed-loop fibre recycling refers to synthetic polymer products such as polyester, nylon and acrylic which will not only be recycled but recyclable in the same production chain for multiple cycles (Payne, 2015). Processing these synthetic materials involves chemically breaking down the fibres, before repolymerisation and extrusion as a new fibre, and spinning into yarn for woven or knitted fabric production. As polymers degrade with each recycling, a challenge has been presented to the industry to produce fibres with equivalent or better quality to virgin materials (Payne, 2015) and utilise a process which creates more carbon savings through recycling than the energy burden to recycle the materials in the first instance.

Sorting and grading process for collected textiles yields an unavoidable waste fraction of low grade textiles, unsuitable for reuse. Currently no markets are established for these items; however an opportunity exists to divert these textiles for use as feedstock in innovative chemical recycling processes currently in development. The EU Resyntex Project (Resyntex, 2018) aims to create a complete reprocessing line to transform such textile waste into secondary raw materials for the textile and chemical industries. The Resyntex process uses biochemical processing to recycle cotton, polyamide, polyester and wool into PET monomers for PET production, glucose for bioethanol, protein hydrolysate for resins and adhesives, and polyamide oligomers for the chemical industry. Worn Again (wornagain.co.uk, 2019) are a circular economy textile brand who aim to recapture polyester and cellulose from pure and blended textiles. The Worn Again process uses post-consumer textile feedstock to produce PET chips and cellulosic outputs that could be re-spun into like new fibres.

A complimentary strategy to these material reprocessing stages is 'Design for Cyclability' (Politowicz, 2013). Through this design strategy, the initial process anticipates the potential for eventual recycling and considers existing garments and products as 'raw materials'. In illustration of this principle, a short-life duration prototype product was created from paper based non-woven textile for closed loop material recovery by Kay Politowicz and Sandy MacLennan. This 'disposable fashion' product shows how circular economy fashion could operate at both 'fast' and 'slow' fashion speeds, to appeal to consumer demand for short-life trend pieces. Indeed, if such considerations are integrated into design processes from the initial conception stage, the design brief then becomes the key opportunity to build in sustainable strategies to meet consumer and user requirements throughout each stage of a circular economy fashion supply chain. The design brief 
should establish common goals for producers to adopt a systems based approach which takes into account material savings, provenance, impact, user behaviour and end-of-life considerations (Lockton et al., 2010; Blizzard and Klotz, 2012; RSA Action Research Centre, 2013; Ellen MacArthur Foundation, 2016; The Great Recovery Project, 2016).

Closing the textiles loop will require advanced and largely automated insights into the origin, flow and composition of discarded textiles. Tracking technologies, such as RFID-, QR- or NFC-tagging, can be expected to play an ever stronger role in the future of textile recycling. Blockchain technology is raising great expectations across the board, as it is expected to revolutionise supply chain transparency and product verification. Blockchain allows to build a securely stored and auditable record of information on where a garment comes from, which materials it contains, which certifications are in place and what its supply chain journey looks like. This technology helps to protect consumers from counterfeited or harmful products. Furthermore, it has the potential to make the job of sorters, graders and recyclers considerably easier as textile products would all carry a "materials passport", enabling direct information exchange between production, consumption and recycling.

\section{Barriers to textile recycling}

This systematic review of literature has shown that despite its growing popularity, the textile industry is faced with numerous challenges such as triggering environmental pollution, noise pollution, deterioration in humans' health and resource limitations (Sandin and Peters, 2018; Guyer et al., 2016; FAO-ICAC, 2015; Patel and Vashi, 2015). Recycling of textile products, as part of the broader transformation from a linear to a circular economy, has been identified as a potential solution to these challenges (Roos et al. 2016; Hawley, 2014).

As far as barriers are concerned, there are numerous obstacles to textile recycling, which on many occasions prompt a low recycling rate (Xiao et al., 2018; Sandin and Peters, 2018). Globally, few countries, if any, are yet able to utilise $50 \%$ or more of their potentially recyclable materials. For instance, less than $12 \%$ of the potentially recyclable materials are collected in Brazil while the rates in South Africa, Russia, and China are 10\%, 11\%, and 20\% respectively. Developed economies such as Canada, France, and Italy have relatively higher rates of $32 \%, 40 \%$, and $43 \%$ respectively (Conke, 2018). In 2008, the textile reuse and recycling rate in the UK increased from 22\% to 33\% (Morley, Bartlett and McGill, 2009). Unfortunately, in recent times, a (10-20) \% decline in textile recycling rate has been observed in the UK and other European countries such as Germany, Spain, Belgium, and France (Jordeva et al., 2015). Only 5\% of waste is recycled in Bosnia and Herzegovina, which is similar to the low rate in other countries in the Balkan region (Anthouli et al., 2013). Some of the major barriers to the optimization of textile recycling are discussed below: 
1. Economic Viability: At present, many recycled textile wastes are unsuitable for multiple recirculation and use. This is largely due to the widespread production of lower-grade products (down-cycling) from textile recycling. Limited recirculation and reuse is not economically viable and discourages investment in textile recycling (Elander and Ljungkvist, 2016). Multiple use of textile fibres is more economically attractive with the potential to encourage greater participation in recycling by various stakeholders. In addition, there is limited demand for recycled textiles (SEPA, 2015), Because virgin or unrecycled textile materials have low market prices. The relatively high prices of some recycled textile fibres are influenced by the high cost of the recycling processes, including transportation, which discourages prospective investors.

2. Composition of textile products: The base components of many textile products make them unsuitable for recycling. For instance, the presence of plastics and metals in textile products are an impediment. According to Marconi et al. (2018), recycling is not always feasible due to difficulties in separating the mix made of various types of polymer with different mechanical and technological properties. Furthermore, increased textile fibre strength complicates the shredding of the fibres (Hawley, 2014). Shredding is necessary to convert used textile material back to raw materials, but this affects product quality (McGregor, 2015). Moreover, many textile products contain chemical materials and dyes, which also hinder recycling by decreasing the value of the output (Elander and Ljungkvist, 2016). Some textile dyes are toxic and carcinogenic (Bhuiyan et al., 2016).

3. Non-availability of recyclable textile materials: The quantity of textile waste that is suitable and accessible for recycling is grossly insufficient. Limited quantity of used textiles and textile waste are collected and sorted for recycling (Tai et al., 2011). This is partly because prevalent fibre blends make it difficult to manage the sorting process (Hawley, 2014). According to Fei et al. (2016), recycling in developed countries is undertaken by formal waste vendors, who are "standardized, specialized enterprises". However, in developing countries, thesource-separation and sorting market is dominated by informal waste vendors and formal sorting operates at a much smaller scale (Fei et al., 2016; Linzner and Salhofer, 2014) that affects the rate of recycling. Informal operators are mainly small-scale and labour-intensive, utilising basic recycling technologies, which significantly lower process efficiency (Xiao et al., 2018). Their varying level of commitment and experience, irregular work hours and inconsistent collection pattern also affect the quality of the collection and sorting of recyclable materials (Conke, 2018).

4. Technological limitations: A major reason for the limited quantity of recyclable materials is the lack of technologies for sorting textile waste in preparation for recycling (Elander and Ljungkvist, 2016). Most existing methods cannot separate dyes and other contaminants from the original fibers (McGregor, 2015). Automated sorting will improve the efficiency of the production process and increase the quantity of textiles that are suitable for recycling. In addition to the challenges of sorting, chemical and mechanical textile recycling technology are also limited, requiring significant investment in research to overcome existing limitations and introduce more efficient and effective techniques. Ouyang and Cao (2012) identified the use of outdated concepts (poor recycling system, outdated development concepts, and disordered marketing rules) as the major barriers to recycling, 
particularly in developing countries. More effective trading of recycled materials can also be facilitated through the use of modern information technologies such as the internet, big data, and mobile phone apps (Xiao et al., 2018).

5. Lack of information and limited public participation: Nixon and Saphores (2009) reported a significant correlation between access to recycling information and citizens' attitude to recycling. Limited public awareness on the merits of recycling contributes immensely to the low recycling rate, causing market inefficiency as well as stakeholders' apathy to large scale investments. Successful policies' implementation depends on the individual behaviour of residents. The best waste recycling policies may be ineffective if there is no corresponding change in citizens' behaviour (Conke, 2018). Similarly, inadequate knowledge of the recyclability of textile materials and on the composition of potentially dangerous components in those materials negatively affects market demand for recycled textiles (SEPA, 2017). According to Jesson et al. (2014), the knowledge barrier (ignorance of what to recycle) and the attitude barrier (non-commitment to the ideals of recycling) are two of the fundamental consumer-related barriers to recycling, confirming WRAP's (2008) earlier findings. Currently, many countries prioritize recycling communal waste such as glass, wood, paper, plastic, and metal, while textile recycling is less prioritized and publicized (Anthouli et al., 2013). Ineffective information dissemination negatively impacts governmental management as well. Regulators are unable to collect sufficient data necessary to formulate appropriate policies and manage the downstream textile recycling industry (Xiao et al., 2018).

6. Poor Coordination, weak policies and standards: Payne (2015) identified uncoordinated collection of waste as a barrier to efficient recycling. The absence of an integrated and well-coordinated framework and policies to enhance the overall efficiency of the textile recycling eco-system negatively affects the industry (Chen et al., 2010). Different components of the value chain work independently, sometimes with conflicting interests. Centralising the operations of these respective components will enable the formulation of harmonised policies and regulations addressing specific industrial standards, technology standards, classification standards and test standards (Xiao et al., 2018). The lack of unified and generally-acceptable standards affects the operation and development of the recycling industry. Quality protocols and standards for recycling carpet waste were non-existent in the UK in the last decade (Morley, Bartlett, and McGill, 2009). Xu and Chen (2018) highlighted that without supportive government policies and standards, the broader recycling industry cannot grow rapidly.

\section{Examples illustrating the socio-economic advantages of textile recycling}

In Brazil there are several projects, brands and stylists working with upcycling in fashion (Table 2). In general, these projects aim to add value and empower consumers, suppliers and involved workers, as well as to reduce waste by reusing and recycling (Baruque-Ramos et al., 2017). These outcomes contribute to improving the quality of life of citizens and bring economic benefits. 
Table 2. Examples of textile reuse and recycling good practices in Brazil

Project

Description

Reuse Fabric

Bank (RFB) (São

Paulo)

Retail Fashion

(São Paulo)

The Brandili

Textile Brand

(Santa Catarina)

The Insecta

Shoes Brand

(Porto Alegre)

The Ecosimple

Brand (São

Paulo)

Bank of Clothing from Caxias-doSul (BCCS) (Rio Grande do Sul)
The RFB aims to prolong the life of scraps, non-used fabrics, stocks, clothes cut or small rolls of fabric. The idea is to make it possible to circulate them again, extending their life cycle through new uses and avoiding burial in landfill. The pieces to be reused are taken to the unit and are prepared and disinfected. After this process, they are ready to be resold. If the user deposits directly the pieces in the Bank, he/she will receive credits for each kilo deposited and which can be used to take out banked fabrics. Usually these users are artisans, fashion students, young designers, wellknown stylists, and even brands considered sustainable. All pieces deposited have an origin registry that allows life cycle mapping. The ethos of the organization is to value the environmental and social dimensions.

This project is the result of a partnership between Sinditêxtil-SP (Union of Spinning and Weaving Industries), theBrazilian Textile Industry Association and São Paulo City Hall, as well as other institutions in an area comprising about 1200 clothing factories. These organizations produce about 12 tons of textile waste daily. The project aims to manage the commercialization of this waste in order to contribute to the reuse of it as raw material and to propose a waste management plan in accordance with the National Solid Waste Policy.

The brand has been producing children's clothing for over 50 years. Recently, it has adopted a sustainability strategy involving natural resources. The company reuses textile waste by partnering with factories that provide raw materials for reuse in ecological yarns production (from textile materials and plastic bottles). Moreover, the reverse logistic is encouraged, and post-consumer distribution channels have enabled a reverse flow of products and materials back to the start of the production cycle.

This vegan company produces footwear having as a premise the defense of animals, avoiding the use of any animal input. Its products are made of used clothing or wastes from fabrics or even recycled PET. Some of the materials are bought in second hand fairs or provided by the Reusable Fabric Bank of São Paulo.

All the production is made of $100 \%$ recycled materials, linking technology with sustainability. The material used is recycled from plastic bottles, discarded clothing or fabric scraps from clothing factories and waste from spinning processes. This brand's approach to innovation is to adopt a production model that reduces environmental impact and helps deprived communities.

This bank provides centralized storage for textile waste from factories of the region. It functions by receiving the waste from the local textile industry; then the types of materials are sorted and organized to send to the registered communities in the system, who reuse these materials. The inputs that cannot be reused go to other industries (e.g. packaging) closing the product cycle. 
Source: Broega et al. (2017)

Additionally, Baruque-Ramos et al. (2017) point out another set of projects carried out in Brazil. For example, COMAS recovers cloth from discarded men's shirts. The "Viver de Costura" ("Living Sewing") social project provides sewing training for women in the Sabara region (state of Minas Gerais). It is closely related to the Centre for Design and Social Responsibility of Design School (State University of Minas Gerais), and aims, not only to teach sewing, but also to contribute to product development with innovative solutions and design. The last example is related with the Association of Brazilian Women Entrepreneurs - AMEBRAS (Rio de Janeiro) which, since 1998, carries out reuse activities on textile materials from the Rio Carnival. It has around 886 associates from different classes and business segments, and has professionally qualified about 22.000 people. The main raw materials for reuse are fabrics, feathers, feathers, sequins and various trims. These materials are obtained in the phase known as "dispersion" of the samba schools.

In the field of textile recycling, other players can be found in the international arena. Thus, despite the several technical, social and economic challenges, diverse brands in Nordic countries have started investing in textile-to-textile recycling (Table 3), responding to an increasing recognition that the industry should take responsibility for reducing its environmental impacts.

Table 3. Examples of "reuse and recycling friendly" Nordic textile brands

\begin{tabular}{|c|c|c|}
\hline Company & Product & Project description \\
\hline $\begin{array}{l}\text { Egetæpper } \\
\text { (Denmark) }\end{array}$ & Carpets & $\begin{array}{l}\text { The company uses recycled fishing nets in carpets and has } \\
\text { a take-back system. It is focused on minimising resource } \\
\text { use and taking responsibility for its products after the point } \\
\text { of sale. }\end{array}$ \\
\hline $\begin{array}{c}H \& M \\
\text { (Sweden) }\end{array}$ & Clothing & $\begin{array}{l}\text { A diversified set of its products include some recycled fibres } \\
\text { as cotton, wool and cashmere, collected from both pre and } \\
\text { post-consumer waste. If a product includes fibres } \\
\text { recovered from used clothes, its tag provides that } \\
\text { information to the consumer. }\end{array}$ \\
\hline $\begin{array}{l}\text { Houdini } \\
\text { (Sweden) }\end{array}$ & $\begin{array}{l}\text { Outdoor } \\
\text { clothing }\end{array}$ & $\begin{array}{l}\text { Houdini collects its used products from consumers for } \\
\text { reuse and recycling. Worn out } 100 \% \text { polyester products are } \\
\text { sent to a factory for recycling. Additionally, the company } \\
\text { uses recycled nylon and polyester recovered from PET } \\
\text { bottles. The brand aims to design for recyclability, keeping } \\
\text { processes, materials and products as simple as possible. }\end{array}$ \\
\hline $\begin{array}{c}\text { Lindex } \\
\text { (Sweden) }\end{array}$ & Clothing & $\begin{array}{l}\text { The company started to promote textile reuse and } \\
\text { recycling in cooperation with Myrorna, a NGO, beginning } \\
\text { with fibers recycled from plastic waste. Lindex also uses } \\
\text { recycled post-consumer denim in its new denim } \\
\text { collections. Its main objective is that by } 2020,80 \% \text { of all its } \\
\text { outfits will be produced more sustainably. }\end{array}$ \\
\hline
\end{tabular}




$\begin{array}{ccc}\begin{array}{c}\text { Nortex } \\ \text { (Denmark) }\end{array} & \begin{array}{l}\text { Duvets and } \\ \text { pillows }\end{array} & \begin{array}{l}\text { A part of the production of duvets, pillows and cushions is } \\ \text { designated by "Nortex Care collection", being directed } \\ \text { mostly to hospitals. Appealing to the health care sector is } \\ \text { challenging, but is necessary to take advantage of the green } \\ \text { procurement trend. }\end{array} \\ \begin{array}{c}\text { Pure Waste } \\ \text { (Finland) }\end{array} & \begin{array}{l}\text { This brand uses its own fibres made from 100\% recycled } \\ \text { materials. In order to get these materials, the company } \\ \text { sources from pre-consumer textile waste and PET fibres } \\ \text { recycled from used plastic bottles. The recyclability of } \\ \text { clothing produced in this factory is also important. Thus, } \\ \text { the designers use strategies like replacing hang labels and } \\ \text { by using as few accessories as possible. Additionally, the } \\ \text { energy efficiency is increased by minimising waste and } \\ \text { packaging. }\end{array}\end{array}$

Source: Watson et al. (2017)

Some of the brands presented above represent a good example of the socio-economic advantages of textile recycling. All are making use of yarns/fabrics with recycled content in selected new products. In fact, reuse was found to provide the greatest benefits, regardless of whether the textiles are reused in the Nordic region or exported for reuse elsewhere (Watson et al., 2016). However, just a part of the companies are developing or are part of closed-loop systems (a brand or some of its partner takes back used products from consumers, for extracting material as input to the next creation of products). According to Newell (2015), retail take-back programs are a great step towards producer environmental awareness and responsibility for waste that the textile sector generates. Further, at the point of sale, the fashion industry has direct contact with clients and consequently has the opportunity to educate consumers on how to recycle textiles.

\section{Lessons Learned}

It is apparent that companies struggle to find value in textile waste. By far the most value is in the sale of products that are unwanted but not worn-out. The global export market for worn and used clothing is estimated to be about \$4bn (WRAP, 2016). However, demand for these products is limited and shrinking. This is illustrated by policies adopted in 2016 by several African countries: Rwanda, Kenya, Uganda, Tanzania, South Sudan and Burundi have announced a block on used garment imports by 2019. There are socio-economic reasons for this: Rwanda's president is reported as saying "We have to grow and establish our industries." (Gittleson, 2018). The consequences for exporting countries is that the value of collected goods has reduced with time, putting pressure on this business sector. In the UK, the Textile Recycling Association has reported a downturn in membership, losing a quarter of its collector and processor companies to bankruptcy or closure in the period 2013-2016 (Martin, 2016). This decline has continued.

Mechanical processing routes yield insulating materials and felts, creating local employment and utilizing local supply chains. In some cases, such as Lindex and Pure Waste, it has been possible to extract fibers and feed them into a local supply chain for fabric production. However, the markets for nonwoven textiles are showing signs of being saturated. Some retail brands, such as H\&M, are incorporating a small percentage of recycled fibers into some of their garments, which helps to create a demand for recycled fibers. However, it is probable that these fibers are from post- 
industrial waste (to avoid degradation and coloration) and there is likely to be a limit on the availability of large volumes of such materials. Where fibers are extracted from fabrics, they are damaged and they often carry dye, limiting their usefulness. With research and development projects, more outlets for these recycled materials could be found, but as risks are high, sources of external funding may be needed to catalyse change.

Upcycling is practiced by a few small companies that are highly motivated to recycle, exemplified by Reuse Fabric Bank, Bank of Clothing, Brandili Textile Brand, Houdini and Lindex. However, volumes are relatively small and upcycled products do not fit readily into the business plans of most clothing retailers. Nevertheless, some retailers have trialed upcycled eco-fashion ranges and a report on the varying degrees of success was published (Mowbray, 2014). It was concluded that using postindustrial waste was the best way to increase volumes of particular styles, and that upcycling businesses should be in partnership with garment manufacturing companies. The report considers that the up-cycling line should be alongside the factory line, with a creative waste manager whose responsibility is to identify waste and surplus fabrics, and to re-route it to the appropriate upcycling team. Some other companies are upcycling with post-consumer wastes, and face rather different challenges with material supply. Some have concluded that upcycling can be economic only when it is located in low labour-cost countries, but this creates new problems for design to address export markets. There is no doubt that the concept of commercial upcycling is in its infancy, but the company cases identified above show that this business model can be viable.

Despite these routes to recycling, it is also apparent that much textile waste is not suitable for processing by any of these options: the materials are damaged by wear and tear; they may be soiled or damp; they may have branding that limits resale; their composition is a blend of fibre types; and there may be metal or plastic elements in the product. With these materials, the baseline costs of collection, sorting and transportation may never be recovered.

Apart from in Scandinavia, consumers do not have a reputation for purchasing products with a sustainability story. Nor do consumers display a good understanding of sustainable ways of disposing of unwanted garments. Knowledge of the environmental impact of clothing and textiles is typically minimal. Consequently, this is an active area of interest, particularly because consumer decisions are crucial for developing a circular economy in textile materials. Educational opportunities are taken by retailers with an ideological commitment to sustainability (such as H\&M, Table 3), but the "value-action" gap is a well-recognised phenomenon (Barr, 2006). Several projects addressing Circular Economy issues include consumers in their research. Aspects of the Resyntex consumer behavior work programme are addressed by Boiten et al. (2017).

Brands seeking to promote the concept of sustainability have sought to remove toxic chemicals from their supply chains. This has made a significant impact, although there is still a long way to go. The problems associated with cotton (pesticides, water usage) are largely untouched. There is a growing willingness for brands to launch products with a component of recycled fibres, and this is certainly a step towards the Circular Economy. Some products have appeared on the market made from $100 \%$ recycled materials (examples are Houdini and Pure Waste). Many retailers are involved in take-back schemes (including H\&M), and are often willing to exchange a gift voucher for a returned garment. The study by Hvass (2014) identified two main ways that retailers are currently taking post-retail responsibility: second hand retailing and product take-back schemes. Take-back appears to be the most significant platform for informing consumers about sustainability and the Circular Economy. 
There is less evidence that High Street brands are changing the way they design their products. Fabric design is still decoupled from garment design (Tyler et al., 2006), so it is difficult for all the relevant issues to be considered when product ranges are being developed. Typically, fashion designers do not involve themselves with Design for the Environment (DfE) or Design for Disassembly (DfD). Design for an extended life, or design for a second life, is given a low priority and is rarely considered when products are developed. Radical design strategies are being developed (Niinimäki \& Hassi, 2011), but brands will determine whether they are used.

Nevertheless, some of the cases outlined earlier (Houdini, Pure Waste) show that, even in small companies, designers can play an important role in developing sustainability stories. Large retailers (such as H\&M) show that moves toward a Circular Economy are possible for garments sold in the High Street. However, the Fashion Sector is buyer-led; the agenda is set by retailers and brands; performance is measured by gross margin. Consequently, the supply chain is not in a position to champion sustainability and the Circular Economy: the leading must come from companies with buying power.

Looking at other industries provides insights into what can be done. Electrical and Electronic consumer products have made greater use of DfE and DfD. Significantly, in the EU, they have been responding to the WEEE Directive, which puts obligations on producers for the products they sell to consumers. These responsibilities include take-back and disposal. Consequently, the affected companies have incorporated these requirements into their design process - and at least parts of the sector have an impressive record of reprocessing returned products and recycling materials and components. Can this be approach be the norm in textile and clothing products? The potential for the textiles and clothing sector is discussed by Bhamra et al. $(1998)$. Bhamra's $(2007,47)$ conclusions include the following: "the electrical, electronic and automotive sectors now face 'Producer Responsibility' Legislation, making them responsible for their products at the end of life, how long will it be before the textile and clothing sector faces similar legislation? The sector will be illprepared when this comes along."

Extended Producer Responsibility (EPR) for textiles and apparel is being considered more widely. It has been introduced in France (in December 2006) and producers are "considered responsible by law for providing or managing the recycling of their products at the end of their usage" (Eco TLC, 2018). Every eligible company that introduces clothing, household linen, and footwear items to the French market has opted to delegate these responsibilities to a not-for-profit private company: Eco TLC. This company manages collection, sorting, R\&D projects (selected by a scientific committee) and initiatives to influence consumer waste sorting habits. Whilst Eco TLC has a commendable track record, there is a major problem with the way EPR has been introduced: the design processes of retailers and brand owners is largely unaffected. Consequently, the potential offered by DfE and DfD is largely untapped. Policy issues, including EPR, are being actively discussed in Sweden (Elander et al., 2017). The conclusion is that an EPR that can affect design has the potential to make large positive impacts on fibre-to-fibre recycling as well as the downstream reprocessing of textile materials.

The present situation is characterised in Section 4 as having "blockages". However, there are new opportunities created by the chemical processing route for textiles that are currently deemed valueless and which are destined for incineration or landfill. The projects identified in Section 3 take these discarded textile products and transform them into industrial feedstocks that have value. Some of these feedstocks can be used to create textile fibers, and others supply markets in other industrial sectors. Whilst feedstocks have value, they are already widely available as commodities and there is price competition. Bearing in mind that there are costs of collection, sorting and 
transport, with additional costs of dye removal, depolymerisation and subsequent conversion to commercial products, the case for investment in these processes is currently unconvincing. Consequently, if policy-makers are seeking to advance circular economy practices in textiles and clothing, some financial drivers are justified. To achieve this, a major option to consider is the introduction of Extended Producer Responsibility in such a way that producers implement design practices that impact recovery of materials at the end-of-life stage of the product life-cycle. Such developments will inevitably lead to the socio-economic benefits of investment, local employment, new business opportunities and the strengthening local supply chains.

\section{Conclusions}

The field of textiles is a consumption area which, along with food, housing and mobility, causes greatest environmental impacts. By means of re-use and recycling, some of these environmental impacts may be reduced. The current available technologies allow both government and business on the one hand, but also consumers on the other, to practice recycling in a way which makes it both environmentally sound, ethically just, and economically acceptable.

There is a great potential for the textile recycling sector to contribute to the circular economy (Baruque-Ramos et al., 2017). It can reduce the production of new textiles from virgin materials and hence reduce the use of water, energy and chemicals in the production chain (Dahlbo et al., 2017). However, textile recycling is still facing a number of challenges, such as limited practical technologies for recycling various types of fibres (Zamani, 2014), technical problems related to the complexity of clothes (Cobbing and Vicaire, 2016), and immature markets. The size of the markets is not large enough to absorb the volume of material that would come from the comprehensive recycling of clothes (Remy et al., 2016), and the utilization of virgin materials such as cotton and crude oil are still more economic than recycling of textile fibres (Peterson, 2015).

For all fibres and recycling methods currently being used, recycling is still a better environmental and socio-economic option, whose benefits far outweigh mere incineration. The socio-economic benefits, although not huge, are sufficient to justify the pursuit of this option on a variety of grounds. In particular, the recycling of wool fibres -which show the largest benefits per tonne- can suggest that wool should receive more attention in future activities. A similar line of thinking applied to polyester fibres. Since these are derived from fossil fuels, their reuse and recycling offers benefits which are on the one hand lower than cotton and wool, but due to the high share of polyester fibres in the textiles market today, are still substantial. The novelty of the paper resides in the fact that it clarifies the content of socio-economic benefits, and identifies the achieved socio-economic benefits while also highlighting others that have yet to be achieved.

A greater emphasis to Extended Producer Responsibility may be useful in that it encourages producers to pursue sustainable design practices, which may reflect positively over the entire product life-cycle. 


\section{References}

Anthouli, A., Aravossis, K., Charitopoulou, R., Tot, B. and Vujic, G. (2013). Opportunities \& barriers of recycling in Balkan countries: The cases of Greece and Serbia. HSWMA, SeSWA, and ISWA

Barr, S. 2006. Environmental Action in the Home: Investigating the 'Value-Action' Gap, Geography, $91(1), 43-54$

Baruque-Ramos, J., Amaral, M.C., Laktim, M.C., Santos, H.N., Araujo, F.B. and Zonatti, W.F. (2017). Social and economic importance of textile reuse and recycling in Brazil, in: IOP Conf. Series: Materials Science and Engineering. Presented at the 17th World Textile Conference AUTEX 2017- Textiles - Shaping the Future, 1-10. Available at: http://dx.doi.org/10.1088/1757$899 \times / 254 / 19 / 192003$

Bhamra, T., Heeley, J. and Tyler, D. (1998). A cross-sectoral approach to new product development. The Design Journal, 1(3), 2-15

Bhuiyan, M.A.R., Rahman, M.M., Shaid, A., Bashar, M.M. and Khan, M.A. (2016). Journal of Cleaner Production, 112 (4), 3063-3071

Bhamra, T. (2007). Building Ecodesign throughout the Supply Chain: A New Imperative for the Textile \& Clothing Industry. In: Miraftab, M., and Horrocks, A.R. Ecotextiles: The Way Forward for Sustainable Development in Textiles, Woodhead Publishing, 41-49.

Bianchi, C. and Birtwistle, G. (2010). Sell, give away, or donate: an exploratory study of fashion clothing disposal behaviour in two countries. The International Review of Retail, Distribution and Consumer Research, 20, 353-368.

Boiten, V.J., Han, S. L-C. and Tyler, D. (2017). Step by step towards the Circular Economy. Textiles, (1), 14-15.

Broega, A.C., Jordão, C. and Martins, S.B. (2017). Textile sustainability: reuse of clean waste from the textile and apparel industry, in: IOP Conf. Series: Materials Science and Engineering. Presented at the 17th World Textile Conference AUTEX 2017- Textiles - Shaping the Future, IOP Publishing, pp. 1-7. Available at: http://dx.doi.org/10.1088/1757-899X/254/19/192006

Bartlett, C., McGill, I. and Willis, P. (2013). Textiles flow and market development opportunities in the UK. Retrieved from www.wrap.org.uk/user/login?destination=system\%2Ffiles\%2Fprivate\%2FTextile+Flowstan $d+$ Market+Development+Opportunities+Updated+June+2013v2.pdf

Blizzard, J. L. and Klotz, L. E. (2012) 'A framework for sustainable whole systems design.' Design Studies. Elsevier Ltd, 33(5), 456-479.

Carney Almroth, B. M., Åström, L., Roslund, S., Petersson, H., Johansson, M. and Persson, N. K. (2018). Quantifying shedding of synthetic fibers from textiles; a source of microplastics released into the environment. Environmental Science and Pollution Research, 25(2), 1191-1199.

Chapagain, A. K., Hoekstra, A. Y., Savenije, H. H. G. and Gautam, R. (2006). The water footprint of cotton consumption: An assessment of the impact of worldwide consumption of cotton products on the water resources in the cotton producing countries. Ecological Economics, 186-203.

Chen, X., Geng, Y., and Fujita, T. (2010). An overview of municipal solid waste management in China. Waste Manage., 30 (4), 716-724

Conke, L.S. (2018). Barriers to waste recycling development: Evidence from Brazil. Resources, Conservation and Recycling, 134, 129-135

Cobbing, M. and Vicaire, Y. (2016). Timeout for fast fashion. Available at: https://www.greenpeace.org/international/Global/international/briefings/toxics/2016/Fac t-Sheet-Timeout-for-fast-fashion.pdf 
Coberec (2016) Press statement "Textielrecyclage in België". Coberec. Available at:

https://coberec.be/nieuwsbericht/textielrecyclage-belgie-500-miljoen-stuksoude-kleren-kregen-een-tweede-leven-2015.

[Accessed May 2018]

Cuc, S., lordănescu, M., Gîrneață, A. and Irinel, M. (2015). Environmental and socioeconomic sustainability through textile recycling. Industria Textila, 66(3), 156-163.

Cuc, S. and Vidovic, M. (2011). Environmental Sustainability through Clothing Recycling. Operations and Supply Chain Management, 4 (2/3), 108-115.

Dahlbo, H., Aalto, K., Eskelinen, H. and Salmenperä, H. (2017). Increasing textile circulationConsequences and requirements. Sustainable Production and Consumption, 9, 44-57.

De Smet, D., Weydts, D. and Vanneste, M. (2015) 'Environmentally friendly fabric finishes.' In Blackburn, R. (ed.) Sustainable Apparel: Production, Processing and Recycling, 3-33.

Eco-TLC (2016) 'Eco-TLC - Rapport d' activité 2015-2016.'

ECOSIGN (2017) Textile recycling as a contribution to circular economy and production waste enhancement. Available at: http://www.ecosign-project.eu/news/textile-recycling-as-acontribution-to-circular-economy-and-production-waste-enhancement/ [Accessed January 2018].

Eco TLC, 2018. Available at: http://www.ecotlc.fr/page-297-information-in-english.html [Accessed May 2018]

Elander, M., Tojo, N., Tekie, H. and Hennlock, M. (2017). Impact assessment of policies promoting fiber-to-fiber recycling of textiles, Mistra Future Fashion report number: 2017:3. Available at: http://mistrafuturefashion.com/wp-content/uploads/2017/06/MFF-report-2017-2Impact-Assessment-of-policies-promoting-fiber-to-fiber-recycling-of-textiles.pdf [Accessed May 2018]

Elander, M. and Ljungkvist, H. (2016). Critical Aspects in Design for Fiber-to-fiber Recycling of Textiles. Available at:

http://mistrafuturefashion.com/wp-content/uploads/2016/06/MFF-report-2016-1-Criticalaspects.pdf

[Accessed April 2018]

Ellen MacArthur Foundation (2016) The New Plastics Economy: Rethinking the future of plastics. p. 120.

Ellen MacArthur Foundation (2017) A New Textiles Economy: Redesigning Fashion's Future, Available at: https://www.ellenmacarthurfoundation.org/publications/a-new-textileseconomy-redesigning-fashions-future [Accessed October 2018]

Ellen McArthur Foundation (2016) The Circular Economy Concept - Regenerative Economy.

Available at: https://www.ellenmacarthurfoundation.org/circular-

economy/overview/concept [Accessed October 2018]

European Commission (2017) Circular economy in practice - reducing textile waste. Available at: https://ec.europa.eu/easme/en/news/circular-economy-practice-reducing-textile-waste [Accessed January 2018].

European Commission (2015a) Fashion and high-end industries in the EU.

European Commission (2015b) Textiles and clothing in the EU.

Available at: http://ec.europa.eu/growth/sectors/fashion/textilesclothing/eu/index_en.htm.

[Accessed October 2018]

European Commission (2015) Circular Economy Closing the Loop. Available at:

http://europa.eu/rapid/press-release_IP-15-6203_en.htm [Accessed October 2018].

FAO-ICAC (2015) Measuring Sustainability in Cotton Farming Systems - towards a Guidance 
Framework.

Available at:

http://www.fao.org/publications/card/en/c/c2658c57-5edd-4bd2-bc0d-024ccd8a9785/

[Accessed April 2018]

Fei, F., Qu, L., Wen, Z., Xue, Y., and Zhang, H. (2016). How to integrate the informal recycling system into municipal solid waste management in developing countries: based on a China's case in Suzhou urban area. Resour. Conserv. Recycl., 110, 74-86

Fischer, A. and Pascucci, S. (2017) Institutional incentives in circular economy transition: The case of material use in the Dutch textile industry. Journal of Cleaner Production, 155 (2), 17-32

García-Granero, E.M., Piedra-Muñoz, L., and Galdeano-Gómez, E. (2018). Eco-innovation measurement: A review of firm performance indicators. Journal of Cleaner Production, 191, 304-317

Gereffi, G. and Frederick, S. (2010) 'The global apparel value chain, trade and the crisis: challenges and opportunities for developing countries.' World Bank Policy Research Working Paper, $1-41$.

Gittleson, K. (2018). BBC News, 31 January. Available at: http://www.bbc.co.uk/news/business42777804 [Accessed May 2018]

Gray, S. (2017) Mapping clothing impacts in Europe: the environmental cost. Banbury: WRAP

Güyer, G.T., Nadeem, K., and Dizge, N. (2016). Recycling of pad-batch washing textile wastewater through advanced oxidation processes and its reusability assessment for Turkish textile industry. Journal of Cleaner Production, 139, 488-494

Hawley, J.M. (2014). Textile Recycling. In: Handbook of Recycling: State-of-the-art for Practitioners, Analysts, and Scientists.

Hvass, K.K. (2014). Post-retail responsibility of garments - a fashion industry perspective, Journal of Fashion Marketing and Management, 18(4), 413 - 430

Jesson, J. et al. (2014). Barriers to Recycling: A Review of Evidence Since 2008 M-E-L Research/WRAP

Jordeva, S., Tomovska, E., Trajković, D. and Zafirova, K. (2015). Current State of Pre-Consumer Apparel Waste Management in Macedonia. FIBRES \& TEXTILES in Eastern Europe. 23, 1(109), 13-16

Kant, R. (2012). 'Textile dyeing industry an environmental hazard.' Natural Science, 4(1), 22-26.

Kim, C.S. and Kim, K.R. (2016). A Case Study Comparing Textile Recycling Systems of Korea and the UK to promote Sustainability. Journal of Textile and Apparel, Technology and Management, 10, 1-11.

Kuo, T.-C. and Smith, S. (2018). A systematic review of technologies involving eco-innovation for enterprises moving towards sustainability. Journal of Cleaner Production, 192, 207-220

Lieder, M. and Rashid, A. (2016). Towards circular economy implementation: a comprehensive review in context of manufacturing industry. Journal of Cleaner Production, 115, 3651

Levy, Y. and Ellis, T.J. (2006). A systems approach to conduct an effective literature review in support of information systems research. Inf. Sci. Int J. Emerg. Transdiscipline, 9, 181-212

Linzner, R., and Salhofer, S. (2014). Municipal solid waste recycling and the significance of informal 
sector in urban China. Waste Manage. Res., 32 (9), 896-907

Lockton, D., Harrison, D. and Stanton, N. A. (2010). The Design with Intent Method: A design tool for influencing user behaviour. Applied Ergonomics, 41(3), 382-392.

Machi, L.A. and McEvoy, B.T. (2009). The Literature Review: Six Steps to Success. Corwin Press, Thousand Oaks, Calif .

Marconi, M., Landi, D., Meo, I. and Germani, M. (2018). Reuse of Tires Textile Fibers in Plastic Compounds: Is this Scenario Environmentally Sustainable? Procedia CIRP, 69, 944-949

Martin, I. (2016). Unwanted 'milestone' for UK textiles recycling sector. Recycling International (June 9). Available at: http://www.recyclinginternational.com/recyclingnews/9708/ferrous-metals/germany/unwanted-039-milestone-039-uk-textiles-recyclingsector [Accessed May 2018]

McGregor, L. (2015). Are Closed Loop Textiles the Future of Fashion? Sourcing Journal. Available at: https://sourcingjournal.com/topics/raw-materials/are-closed-loop-textiles-the-futureof-fashion-36800/

[Accessed April 2018]

McKinsey (2015). Europe's circular economy opportunity. Available at https://www.mckinsey.com/business-functions/sustainability-and-resourceproductivity/our-insights/europes-circular-economy-opportunity [Accessed November 2018]

Michaud, J.-C., Farrant, L., Jan, O., Kjær, B., Bakas, I., Michaud, J.-C., Farrant, L., Jan, O., Kjær, B. and Bakas, I. (2010). Environmental benefits of recycling - 2010 update.

Mwinyihija, M. (2010). Ecotoxicological Diagnosis in the Tanning Industry. Springer Science and Business Media, 17.

Mowbray, J. (2014). Investment required to make upcycling viable. Ecotextile News, (April)

Morley, N.J., Bartlett, C. and McGill, I. (2009). Maximising Reuse and Recycling of UK Clothing and Textiles: A report to the Department for Environment, Food and Rural Affairs. Oakdene Hollins Ltd

Newell, A. S. (2015). Textile waste resource recovery: a case study of New York State's textile recycling system. Thesis presented in the Faculty of the Graduate School of Cornell University.

Niinimäki, K. and Hassi, L. (2011). Emerging design strategies in sustainable production and consumption of textiles and clothing, Journal of Cleaner Production, 19, 1876-1883.

Nixon, H. and Saphores, J.-D.M. (2009). Information and the decision to recycle: results from a survey of US households. J. Environ. Plann. Manage., 52 (2), 257-277

Nunes, L.J.R., Godina, R., Matias, J.C.O. and Catalao, J.P.S. (2018). Economic and environmental benefits of using textile waste for the production of thermal energy. Journal of Cleaner Production, 171, 1353-1360.

Ouyang, P. and Cao, Z. (2012). Current status, problems and path selection for recycling system construction in China. Recycl. Resour. Circ. Econ., 5 (7), 21-24

Oakdene Hollins. (2016). Chemical recycling - A solution for Europe's waste textile mountain? Available at: https://www.oakdenehollins.com/reports/2016/12/16/chemical-recycling-asolution-for-europes-waste-textile-mountain

Patel, H. and Vashi, R.T. (2015). Batch Adsorption Treatment of Textile Wastewater. In: Characterization and Treatment of Textile Wastewater. B-H, Elsevier.

PATAGONIA (2017). How to Recycle Patagonia Garments. Available at: http://www.patagonia.com/recycling.html [Accessed January 2018].

Payne, A. (2015). Open and closed-loop recycling of textile and apparel products. In Muthu, S. (Ed.) 
Handbook of Life Cycle Assessment (LCA) of Textiles and Clothing. Woodhead Publishing, Cambridge, United Kingdom, 103-123.

Pellizari, F., Scheffer, M. and Rosendo, H. (2011). In-Depth Assessment of the Situation of the Textile and Clothing Sector in the EU and Prospects. EUROPEAN COMMISSION ENTERPRISE AND INDUSTRY DG.

Pensupa, N., Leu, S.-Y., Hu, Y., Du, C., Liu, H., Jing, H., Wang, H. and Lin, C. S. K. (2017). Recent Trends in Sustainable Textile Waste Recycling Methods: Current Situation and Future Prospects. Topics in Current Chemistry. Springer International Publishing, 375(5), 76.

Piontek, F. M. and Müller, M. (2018). Literature reviews: Life Cycle Assessment in the context of Product-Service Systems and the Textile Industry. In Procedia CIRP. Copenhagen, Denmark: The Author(s), 758-763.

Politowicz, K. (2013). Design Lifetimes: A Manifesto for Strategic Change.

Remy, N., Speelman, E. and Swartz, S. (2016). Style that's sustainable: A new fast-fashion formula. Available at: https://www.mckinsey.com/business-functions/sustainability-and-resourceproductivity/our-insights/style-thats-sustainable-a-new-fast-fashionformula?cid=sustainability-eml-alt-mip-mck-oth-1610 [Accessed January 2, 2018].

Resyntex (2018) Resyntex: A New Circular Economy Concept. Available at:

http://www.resyntex.eu/images/downloads/RESYNTEX-Leaflet-2018.pdf [Accessed January 2019]

Ribeiro Rosa, A.M. 2016. Circular Economy in the Clothing Industry: Challenges and Strategies, Master of Science Thesis, 2016, KTH Industrial Engineering and Management, Stockholm. Available at: http://www.diva-portal.org/smash/get/diva2:1037685/FULLTEXT01.pdf

Roos, S., Zamani, B., Sandin, G. and Peters, G.M. (2016). A life cycle assessment (LCA)-based approach to guiding an industry sector towards sustainability: the case of the Swedish apparel sector. Journal of Cleaner Production, 133, 691-700

RSA Action Research Centre (2013) Investigating the role of design in the circular economy.

Sandin, G. and Peters, G. M. (2018). Environmental impact of textile reuse and recycling - A review. Journal of Cleaner Production, 184, 353-365.

Schmidt, A., Watson, D., Roos, S., Askham, C. and Brunn Poulsen, P. (2016). Gaining benefits from discarded textiles: LCA of different treatment pathways TemaNord report from Nordic Council of Ministers.

SEPA (2015) Circular Economy-elements for the new proposal. Available at: http://www.naturvardsverket.se/upload/miljoarbete-i-samhallet/miljoarbete-i-eu/cirkularekonomi/sveriges-standpunkt-eu-kommissionen-cirkul\%C3\%A4r\%20ekonomi-150626.pdf [Accessed April 2018]

Statista (2018) Global apparel market size projections from 2012 to 2025, by region (in billion U.S. dollars). Available at: https://www.statista.com/statistics/279757/apparel-market-sizeprojections-by-region/ [Accessed January 2018].

Tai, J., Zhang, W., Che, Y. and Feng, D. (2011). Municipal solid waste source-separated collection in China: a comparative analysis. Waste Manage., 31 (8), 1673-1682

The Great Recovery Project (2016) Designing for a circular economy: Lessons from The Great Recovery 2012 - 2016 (March).

Tyler, D., Heeley, J. and Bhamra, T. (2006). Supply chain influences on new product development in fashion clothing, Journal of Fashion Marketing and Management, 10(3), 316-328. 
U.S. EPA (2016) Advancing Sustainable Materials Management: 2014 Fact Sheet. United States Environmental Protection Agency, Washington, DC. Available at:

https://www.epa.gov/sites/production/files/2016-

11/documents/2014_smmfactsheet_508.pdf

Watson, D., Gylling, A.C., Andersson, T., Elander, M. and Heikkilä, P. (2017). Textile-to-textile recycling. Ten Nordic brands that are leading the way. Nordic Council of Ministers, Copenhagen, Denmark. Available at: www.norden.org/nordpub

Wijkman, A. and Skånberg, K. (2016). The Circular Economy and Benefits for Society. Club of Rome

and Mava Foundation. Available at https://www.clubofrome.org/wp-

content/uploads/2016/03/The-Circular-Economy-and-Benefits-for-Society.pdf

Worn Again (2015) Available at http://wornagain.info/. [Accessed September 2015]

WRAP (2018) WRAP research shows four main barriers to recycling. Available at:

http://www.wrap.org.uk/content/wrap-research-shows-four-main-barriers-recycling [Accessed April 2018]

WRAP (2016) Textiles Market Situation Report. Available at:

http://www.wrap.org.uk/sites/files/wrap/Textiles_Market_Situation_Report_2016.pdf

WRAP (2014) Evaluation of the end markets for textile rag and fibre within the UK. Available at: http://www.wrap.org.uk/sites/files/wrap/priv_download/MPD007-

015_Evaluation\%20of\%20End\%20Markets_Final.pdf

$\mathrm{Xu}, \mathrm{X}$-L. and Chen, H.H. (2018). Examining the efficiency of biomass energy: Evidence from the Chinese recycling industry. Energy Policy, 119, 77-86

Xiao, S., Dong, H., Geng, Y. and Brander, M. (2018). An overview of China's recyclable waste recycling and recommendations for integrated solutions. Resources, Conservation and Recycling, 134, 112-120

Zamani, B. (2014). Towards Understanding Sustainable Textile Waste Management: Environmental impacts and social indicators. Thesis submitted to Chalmers University of Technology, Gothenburg, Sweden. Available at:

http://publications.lib.chalmers.se/records/fulltext/204502/204502.pdf 